Александра Латьшева

\title{
ЭТО НЕ ПРОСТО БИЗНЕС: СОЦИАЛЬНАЯ СОСТАВЛЯЮЩАЯ РОССИЙСКОГО КРАУДФАНДИНГА
}

Рассматривая историю появления термина «краудфандинг», я анализирую основные теоретические подходы к определению краудфандинга. Вопервых, как бизнес-инструмента для сбора средств на «стартапы». Вовторых, как элемента альтернативной экономики, когда крауд-спонсоры организуют сообщество вокруг своей площадки, чтобы произвести нужный продукт или услугу. В-третьих, в контексте социокультурного значения этого явления. Как отмечают многие российские исследователи, большинство крауд-спонсоров имеют нематериальную мотивацию, которая игнорируется при изучении краудфандинга исключительно как инструмента для товарно-денежного обмена. Я предлагаю определение краудфандинга, аккумулирующее разные точки зрения, и характеризую ведущие зарубежные краудфандинговые платформы (Kickstarter и IndieGoGo), перечисляю специализированные площадки, разбираю особенности крупнейших российских краудфандинговых платформ (Planeta.ru и Boomstarter). В качестве примера специализированной российской площадки предлагаю рассмотреть проект Sbor-nik, занимающийся сбором средств для издания книг. Для каждой из платформ привожу данные по количеству запущенных проектов, активных пользователей и собранных средств. Отдельно уделяется внимание нематериальной мотивации пользователей: привожу примеры социальных и благотворительных проектов, размещенных на перечисленных выше площадках, а также ситуации, когда пользователи отказывались от вознаграждений или выбирали нематериальные формы вознаграждений (благодарность, упоминание в числе спонсоров). Особо акцентирую внимание на социокультурных особенностях предпочтений спонсоров. Анализирую особенности требований площадок, их самопозиционирования и проектов, размещаемых на них. Сделана попытка ответить на вопросы, что такое краудфандинг как общественное и культурное явление и в чем заключаются его особенности в России. Это явление можно рассматривать как средство, которое выбирают пользователи, чтобы компенсировать недостатки государственной социальной и культурной политики.

Ключевые слова: краудфандинг, краудсорсинг, краудинвестинг, информационные технологии, социокультурные инструменты

DOI: $10.17323 / 727-0634-2017-15-4-660-668$

Александра Николаевна Латышева - аспирант, Институт общественных наук, Российская академия народного хозяйства и государственной службы при Президенте РФ (РАНХиГС); продюсер, АО «Первый канал. Всемирная сеть» (Первый Digital), Москва, Россия. Электронная почта: sasha.latysheva@yandex.ru 
В России первые платформы для краудфандинга появились в 2011 г. C тех пор только один pecypc, Planeta.ru, помог собрать свыше 600 млн рублей, а число зарегистрированных пользователей на Planeta.ru превысило 500 тыс. (Planeta.ru 2016). Сейчас российский рынок краудфандинга расширяется: по данным РБК, за 11 месяцев 2016 г. «сборы на Planeta.ru выросли на 27\% по сравнению с аналогичным периодом 2015 года, а число поддержавших крауд-проекты спонсоров - почти на $36 \%<$. . > Краудфандинговая площадка Boomstarter.ru в 2016 году нарастила объем взносов на 40\% по сравнению с 11 месяцами 2015 года, до 140 млн руб.» (Папандина 2016).

В связи с нарастающей популярностью этой сферы представляется важным проанализировать академические подходы к определению краудфандинга, сделать обзор основных российских краудфандинговых платформ, а также определить роль социальной составляющей российских краудфандинговых проектов.

\section{Проблемы определения краудфандинга}

Меценатство и сбор средств для общественных нужд силами граждан не является новым явлением. Краудфандинг представляет собой новую форму меценатства, позволяет регулярно создавать большие проекты с гражданским финансированием. Эксперты журнала Forbes оценивают объемы средств, привлеченных за 2015 г. краудсорсинговыми платформами, в 34 млрд долларов (Barnett 2016). Термин «краудфандинг» происходит от понятия «краудсорсинг» (от англ. 'crowd' - толпа, 'source' - происхождение), впервые предложенного Джеффом Хоувом, редактором журнала Wired, в 2006 г. (Howe 2006). Хоув анализировал развитие компаний, которые успешно прибегали к помощи любителей-непрофессионалов со всего мира. Компания дает задание неопределенному числу добровольцев, тот, кто справится с заданием, получает вознаграждение (если оно предполагается). В числе наиболее типичных краудсорсинговых проектов Хоув называет интернет-энциклопедию «Википедия» и интернет-аукцион $е B a y$.

Краудфандинг рассматривается как одна из форм краудсорсинга. Этот термин впервые озвучен в 2006 г. интернет-предпринимателем Майклом Салливаном (Word Spy 2008), занимавшимся созданием сайта Fundavlog для аудио- и видеоблоггинга. Где предусмотрена возможность делать пожертвования в поддержку блоггеров - она и получила название «краудфандинг». В широкое употребление термин вошел через несколько лет, когда были запущены платформы IndieGoGo и Kickstarter.

В ситуации краудфандинга «толпа» финансирует проект заказчика. В обмен, как правило, крауд-спонсоры получают вознаграждение, символическое или материальное, соответствующее сумме пожертвования. Вознаграждение может и отсутствовать, тогда финансирование - полностью безвозмездно. 
Существует две основные группы академических определений краудфандинга. К первой группе относятся работы (преимущественно англоязычные), в которых краудфандинг рассматривается как новый эффективный инструмент для интернет-предпринимателей и микроинвестирования. Американские исследователи проанализировали около семисот статей, имеющих отношение к краудфандингу, с целью классифицировать определения этого феномена (Beaulieu et al. 2015). Они отмечают, что большинство работ оказались из сферы бизнес-дисциплин, поэтому краудфандинг рассматривается в них как инструмент для малого бизнеса и стартапов в этой сфере (Ibid: 7).

Однако эта точка зрения является ограниченной. Во-первых, большая часть проектов на краудфандинговых сайтах относятся не к бизнес-категории, а к категории креативных индустрий, таких как «дизайн, создание фильмов, музыкальные перформансы и продюсирование, фотография» (Sigar 2012:479). Эти же сферы деятельности доминируют и в России: на сайте Planeta.ru по сборам лидируют проекты в категориях «кино» и «музыка» (Planeta.ru 2016).

Во-вторых, вознаграждения, которые авторы проектов предлагают своим крауд-спонсорам, чаще всего существенно меньше той суммы, которую жертвуют пользователи. Также у пользователей есть возможность отказаться от награды, а у авторов при составлении проекта - добавить вариант помощи «без награды», который достаточно популярен у крауд-спонсоров. Наконец, сравнивать краудфандинг и бизнес-инвестирование некорректно, так как во втором случае инвестор получает долю в компании и в случае успеха бизнеса возможность вернуть инвестиции и получить доход, тогда как крауд-спонсор в лучшем случае получает инновационный продукт.

Тем не менее невозможно отрицать наличие экономической составляющей в краудфандинге. В связи с этим второе академическое определение краудфандинга следует рассматривать в рамках концепции альтернативной экономики, которую, в частности, изучал Мануэль Кастельс. В исследовании последствий финансового и экономического кризиса 2008 г. автор отметил появление новой экономической культуры, основанной на «ценности жизни как превосходящей формы человеческой организации» (Castells et al. 2012: 13). Он рассматривал различные экономические практики людей, оказавшихся жертвами кризиса. Например, в Каталонии местные общины сообща распределяли внутри сообщества различные продукты и услуги, используя бартер. Такое взаимодействие больше похоже на ситуацию краудфандинга: люди объединяются в сообщества, чтобы получить нужный им продукт или услугу.

Краудфандинговые платформы (Kickstarter и IndieGoGo) открыты в 2008-2009 гг, а первые проекты организованы вокруг уже существующих сообществ, которым была нужна площадка для сбора средств, чтобы создать некий нужный всем участникам продукт. Например, один из ведущих российских краудфандинговых ресурсов, Planeta.ru, стартовал со сбора 
денег на выпуск альбома Spirit группы «БИ-2» (Planeta.ru 2016). Кроме того, вторая группа определений краудфандинга, социокультурная, представлена работами ряда российских исследователей, которые обращают внимание на то, что краудфандинг позволяет людям с общими интересами объединить свои усилия и финансы для создания продукта или услуги, ценного для них. Анна Кочиева пишет: «Чаще всего доноры не имеют четкой цели получения экономического эффекта лично для себя, а средства направляются в проект на безвозмездной основе, либо в обмен на экземпляры продукции или прочих индивидуальных условиях сделки» (Кочиева 2014:32). Вознаграждение само по себе не является основной мотивацией для поддержки проекта. Сергей Седельников считает, что развитие краудфандинга связано с тем, что этот инструмент дает человеку возможность внести вклад в общее дело (Седельников 2015: 156).

Таким образом, взаимоотношения спонсоров и авторов проектов невозможно свести к товарно-денежному обмену. Краудфандинг - это инструмент альтернативной экономики, способ взаимодействия авторов проектов и пользователей, который позволяет им объединяться на специализированных интернет-площадках для создания какого-либо продукта или услуги, представляющей для них особую ценность.

\section{Особенности зарубежных и российских краудфандинговых платформ}

Краудфандинговые платформы - это сайты-посредники, которые предоставляют проектам пространство и инструменты для презентации, привлечения аудитории и осуществления платежей в обмен на комиссию (как правило, от 5 до 15 процентов от собранной суммы, если проект оказался успешным). Крупнейшими краудфандинговыми площадками в мире являются Kickstarter и IndieGoGo. Первый был открыт в апреле 2009 г., и с тех пор, согласно данным площадки, 12 млн человек поддержали проекты на общую сумму 2,8 млрд долларов, а около 120 тыс. проектов завершили сбор средств успешно (Kickstarter 2017). Kickstarter пользуется популярностью у музыкантов, художников, дизайнеров, иллюстраторов, писателей, промоутеров. Сайт работает по модели «все или ничего» - автор проекта получит деньги только в случае, если проект соберет сумму, равную или превышающую заявленную.

IndieGoGo основан в 2008 г. Ресурс привлек 2,29 млрд долларов с помощью 113 тысяч проектов, около $35 \%$ проектов стали успешными (Art of the Kickstarter 2016). В отличие от Kickstarter, авторы проектов на IndieGoGo имеют возможность забрать деньги, даже если финансовая цель не была достигнута. В США также существует ряд тематических площадок, например, Barnraiser (сельское хозяйство), Medstartr (медицина), CoinFunder (биткоинты), Experiment (наука) и др. 
В России действуют две крупные площадки - Planeta.ru и Boomstarter и несколько более мелких. Небольшие закрываются довольно быстро, рынок тематических краудфандинговых сайтов не устоялся. Ресурс Planeta.ru открыт в 2012 г., по данным администрации Planeta.ru, с тех пор им удалось собрать свыше 600 млн рублей. Пользователи создали около 9 тысяч проектов, каждый третий - успешный. На сайте зарегистрировано свыше 500 тысяч пользователей, из которых $40 \%$ женщины, $60 \%$ - мужчины. Средняя сумма пожертвований - 1500 рублей (Planeta.ru 2016). На этой площадке проект считается успешным, если собрал требуемую сумму, однако автор на свое усмотрение может забрать пожертвования при достижении $50 \%$ барьера, но комиссионный процент площадки при этом возрастает.

Ресурс позволяет создавать проекты разных жанров и тем: анимация, бизнес, благотворительность, видео, дизайн, еда, журналистика, игры, искусство, кино, литература, мода, музыка, наука, общество, преактум (предпринимательская активация ума), путешествия, социальное предпринимательство, спорт, танцы, театр, технологии, фотография и др. По словам администрации сайта, «по сборам лидируют творческие проекты, в основном, в категориях «кино» и «музыка»» (Planeta.ru 2016). На сайте есть раздел «Благотворительность», где все проекты успешны по умолчанию, и с них не берется сервисных сбор: авторам выплачивается все пожертвования, независимо от того, удалось ли достичь «несгораемой» суммы. Однако проект должен быть запущен благотворительным фондом, физические лица в этой категории стать авторами не могут. По словам создателей сайта, от 40 до $50 \%$ таких проектов достигают финансовой цели (Planeta.ru 2016).

Во многих краудфандинговых кампаниях большинство вознаграждений - символические. Например, проект «Электроприставка UNA малышка на миллион!» (производство электрических приставок для инвалидных колясок) установил 18 лотов вознаграждений, из них 11 предлагают какой-либо продукт в подарок - от билетов в кино до, собственно, электроприставок в различной комплектации. Однако из 134 пользователей, поддержавших проект в первые 20 дней, 96 (две трети) выбрали опцию без вознаграждения или с символической наградой (публикация имени спонсора на сайте компании).

Другая популярная российская площадка - Boomstarter-официально запущена в 2012 г. Она собрала не менее 300 млн рублей, а количество успешных проектов на ней - не менее 1300 (Boomstarter 2015). В 2016 г. площадка привлекла 140 млн рублей, что на $40 \%$ больше, чем в 2015 г. (Папандина 2016). Автор проекта получает деньги спонсоров только в том случае, если соберет всю заявленную сумму. Длительность проекта составляет 45-60 дней, но в 2017 г. появилась возможность делать бессрочные проекты. Создатели Boomstarter позиционируют платформу как инструмент для предпринимателей: 
С помощью коллективного финансирования вы можете решить сразу ряд задач: получить необходимое финансирование и первых покупателей, узнать, насколько хороша ваша идея, рассказать о своем проекте широкой аудитории и получить бесплатные публикации в СМИ (Boomstarter 2015).

При этом инвестиционные проекты (где в качестве вознаграждений предлагается купить долю, акции или участвовать в получении дивидендов) Boomstarter не принимает к размещению. Помимо этого, не допускаются проекты, связанные с благотворительностью и целевым финансированием (например, сбор средств на финансирование лечения, для благотворительных организаций, стипендий, проведение информационных и агитационных кампаний). Разрешены проекты, которые создаются только в одной из нескольких категорий: искусство, танцы, дизайн, мода, фильмы, еда, игры, музыка, фотография, издательское дело, технологии, театр, спорт. Самые популярные тематики проектов - настольные игры, книги и фильмы (Boomstarter 2015).

Bсе же на площадке можно найти ряд некоммерческих инициатив, которые так или иначе можно отнести к категории благотворительных, например, проект «Котопомощь библиотеке деревни Тимково» - сбор средств для покупки книг в сельскую библиотеку; или кампания «Восстановление лесов острова Ольхон на Байкале». Причем, если в первом случае автор придумала подарки спонсорам (открытки, книги), то во втором вознаграждениями были сертификаты о посадке определенного количества сосен и лиственниц, фотографии и благодарности от авторов.

Одной из немногих российских специализированных площадок является Sbor-nik - сайт для издания электронных книг, запущенный в 2015 г. С тех пор на сайте было собрано чуть больше миллиона рублей и выставлено 44 книги в следующих жанрах: современная проза, фантастика, детектив, женская проза, юмор, поэзия, научно-популярная литература, публицистика, научные издания, справочники и руководства, детские издания (данные на март 2017 г. на основании собственного анализа автором открытой информации площадки). Для сбора денег на издание можно выставить произведение любого жанра. Это может быть как уже готовое произведение, так и незавершенное, но написанное как минимум на четверть от предполагаемого объема книги. Автор должен предлагать собственное произведение, ранее не публиковавшееся в полном объеме, и обеспечить всех своих спонсоров электронной версией книги. При создании проекта автор выкладывает отрывок своего произведения.

Минимальная цель сбора - одна тысяча рублей. Автор получает пожертвованные деньги в случае, если соберет требуемую сумму или если его поддержат не менее 30 человек на сумму не менее 10 тысяч рублей - тогда он получает все, вне зависимости от конечной цели. В случае успеха книга выкладывается на сайте Sbor-nik в электронном виде в свободном доступе на один год. Для новых читателей предусмотрена возможность дополнительно 
перечислить автору материальное вознаграждение. Автор передает сайту только неэксклюзивные права, то есть может предлагать книгу издательствам, самостоятельно продавать ее на любых площадках.

Создатель Sbor-nik Вадим Нестеров считает, что тематическая «книжная» площадка работает эффективней, чем большие ресурсы, так как позволяет создать сообщество: «Если будет площадка, куда много авторов будут приводить свою аудиторию, то путем взаимного перетекания в выигрыше окажутся все - аудитория у авторов увеличится, читатели получат больше интересных книг» (Sbor-nik 2015). Также Нестеров отмечает, что Sbor-nik может предоставлять молодым авторам возможность попробовать свои силы и привлечь аудиторию.

К сожалению, по сборам этот ресурс отстает от ведущих российских краудфандинговых площадок. Тем не менее большинство проектов получают поддержку. Это показывает, что интерес к проекту существует, и, возможно, в будущем данная площадка сможет выйти на более высокий уровень, особенно если ею заинтересуются представители книжного бизнеса.

$$
* * *
$$

Несмотря на различные подходы российских краудфандинговых площадок к позиционированию, большинство успешных проектов связаны с творческой сферой - это кино, музыка, игры. Интерес спонсоров также вызывают социальные и благотворительные инициативы. Популярность символических вознаграждений в некоторых проектах подкрепляет общую тенденцию.

Очевидно, что краудфандинг, хотя и может служить хорошим инструментом по сбору средств для малого бизнеса, тем не менее пока выбирается российскими спонсорами как инструмент решения социальных проблем. Это отражается и на направлении осмысления явления, которое выбрали многие отечественные исследователи - они рассматривают краудфандинг как социальный и культурный феномен, акцентируя внимание на нематериальной мотивации пользователей.

Таким образом, краудфандинг в России - это не просто новый бизнесинструмент для привлечения инвестиций, это, скорее, возможность компенсировать недостатки государственной социальной и культурной политики, развивающаяся благодаря нематериальной мотивации пользователей, готовых поддерживать проекты, которые они считают важными и нужными для общества.

\section{Список источников}

Boomstarter (2015) Бесплатный обучающий онлайн-курс «Мастер краудфандинга». Доступно по ссылке: https://boomstarter.ru/crowd_learning/lessons (дата обращения: 24 марта 2017).

Planeta.ru (2016) $O$ «Планете». Доступно по ссылке: https:/planeta.ru/about (дата обращения: 15 марта 2017).

Sbor-nik (2015) Манифест. Доступно по ссылке: http://sbor-nik.appspot.com/read/sys manifest (дата обращения: 24 марта 2017). 
Папандина А. (2016) Вложения россиян в краудфандинговые проекты в 2016 году выросли на 70\%. Доступно по ссылке: http://www.rbc.ru/business/29/11/2016/583c4b289a79475b477fa6e6 (дата обращения: 24 марта 2017).

Кочиева А.К. (2014) Краудфандинг как современная форма привлечения финансовых ресурсов. Экономика: теория и практика, (1):32-37.

Седельников С.Р. (2015) Краудфандинг как инструмент финансирования стартапов в Российской Федерации. Проблемы современной экономики, 4 (56): 154-157.

Art of the Kickstarter (2016) Kickstarter vs Indiegogo: Which Crowdfunding Platform is Better? Available at: https://artofthekickstart.com/kickstarter-vs-indiegogo-and-how-to-decide-for-yourcrowdfunding-campaign/_(accessed 24 March 2017).

Barnett C. (2016) Trends Show Crowdfunding to Surpass VC in 2016. Forbes. Available at: http:// www.forbes.com/sites/chancebarnett/2015/06/09/trends-show-crowdfunding-to-surpass-vcin-2016/\#50da235d444b (accessed 24 March 2017).

Beaulieu T., Sarker S., Sarker S. (2015) A Conceptual Framework for Understanding Crowdfunding. Communications of the Association for Information Systems, (37):2-37.

Castells M., Caraça J., Cardoso G. (2012) Aftermath: the cultures of the economic crisis, Oxford: Oxford University Press.

Howe J. (2006) The Rise of Crowdsourcing. Wired. Available at: https://www.wired.com/2006/06/ crowds/ (accessed 24 March 2017).

Kickstarter (2017) Stats. Available at: https://www.kickstarter.com/help/stats?ref=hello (accessed 24 March 2017).

Sigar K. (2012) Fret no more: inapplicability of crowdfunding concerns in the internet age and the JOBS Act's safeguards. Administrative Law Review, 2 (64): 474-505.

Word Spy (2008) Crowdfunding. Available at: http://wordspy.com/index.php?word=crowdfunding (accessed 24 March 2017).

Aleksandra Latysheva

\section{NOT JUST A BUSINESS: \\ THE SOCIAL COMPONENTS OF RUSSIAN CROWDFUNDING}

In this overview, I examine the history of the term 'crowdfunding' and analyze different theoretical approaches to its definition. This term primarily refers to a business tactic. Many crowdfunding projects are related to multimedia: music, video-games, book publishing and so on. As mentioned in the work of Manuel Castells, crowdfunding is about alternative economic processes. Sponsors organize their community within one platform so as to facilitate the creation of a product or service that they desire. As many Russian researchers note, most sponsors of crowdfunding projects have a motivation that transcends the purely material, which is lost when examining the phenomenon of crowdfunding as a simple exchange of money for goods and services. I highlight the advantages of the latter approach and propose a definition which unites different points of view. I categorize leading Western crowdfunding platforms (Kickstarter and IndieGoGo), list preeminent specialized platforms, perform an in-depth analysis of the largest Russian crowdfunding services (Planeta.ru and Boomstarter). In addition, I examine the website Sbor-nik, which is used

Aleksandra N. Latysheva - PhD Student, School of Public Policy, The Russian Presidential Academy of National Economy and Public Administration (RANEPA), digital producer, Channel One Russia Worldwide, Moscow, Russian Federatiion. E-mail: sasha.latysheva@yandex.ru 
to crowdfund the publishing of books, as an example of a specialized platform. Statistics regarding the number of projects launched, active users and funds collected are presented for each platform. Particular attention is paid to nonmaterial motivations of users: I present examples of social and charity projects in the abovementioned platforms, as well as cases where users actually refused material rewards or chose non-material ones. I highlight the socio-cultural preferences of backers and sponsors on various platforms. Finally, I attempt to define crowdfunding as a societal and cultural phenomenon, and analyze the particularities of crowdfunding in Russia. I argue that crowdfunding is viewed by its sponsors as a supplementary method of funding important projects in areas, where social and cultural policies of the state fail.

Keywords: crowdfunding, crowdsourcing, crowd investing, IT, social and cultural phenomenon

DOI: $10.17323 / 727-0634-2017-15-4-660-668$

\section{References}

Art of the Kickstarter (2016) Kickstarter vs Indiegogo: Which Crowdfunding Platform is Better? Available at: https://artofthekickstart.com/kickstarter-vs-indiegogo-and-how-to-decide-for-yourcrowdfunding-campaign/_(accessed 24 March 2017).

Barnett C. (2016) Trends Show Crowdfunding to Surpass VC in 2016. Forbes. Available at: http:// www.forbes.com/sites/chancebarnett/2015/06/09/trends-show-crowdfunding-to-surpass-vcin-2016/\#50da235d444b (accessed: 24.03.2017).

Beaulieu T., Sarker S., Sarker S. (2015) A Conceptual Framework for Understanding Crowdfunding. Communications of the Association for Information Systems, (37):2-37.

Castells M., Caraça J., Cardoso G. (2012) Aftermath: the Cultures of the Economic Crisis, Oxford: Oxford University Press.

Boomstarter (2015) Besplatnyj obuchajushhij onlajn-kurs 'Master kraudfandinga' [Free Online Course 'Tthe Master at Crowdfunding']. Available at: https://boomstarter.ru/crowd_learning/lessons (accessed 24 March 2017).

Howe J. (2006) The Rise of Crowdsourcing. Wired. Available at: https://www.wired.com/2006/06/ crowds/ (accessed: 24.03.2017).

Kickstarter (2017) Stats. Available at: https:/www.kickstarter.com/help/stats?ref=hello (accessed 24 March 2017).

Kochieva A.K. (2014) Kraudfanding kak sovremennaja forma privlechenija finansovyh resursov [Crowdfunding as a Mmodern Form of Investment]. Ekonomika: teoriya i praktika [Economics: Theory and Practice], (1):32-37.

Papandina A. (2016) Vlozhenija rossijan v kraudfandingovye proekty v 2016 godu vyrosli na $70 \%$ [Russian Crowdfunding Investment Grows $70 \%$ in 2016]. Available at: http://www.rbc. ru/business/29/11/2016/583c4b289a79475b477fa6e6 (accessed 24 March 2017).

Planeta.ru (2016) $O$ «Planete» [About Planeta]. Available at: https://planeta.ru/about (accessed 15 March 2017).

Sbor-nik (2015) Manifest [The Manifesto]. Available at: http://sbor-nik.appspot.com/read/sys manifest (accessed 24 March 2017).

Sedel'nikov S.R. (2015) Kraudfanding kak instrument finansirovanija startapov v Rossijskoj Federacii [Crowdfunding as an Investment Instrument for Start-Ups in Russian Federation]. Problemy sovremennoy ekonomiki [Problems of Modern Economics], 4 (56): 154-157.

Sigar K. (2012) Fret No More: Inapplicability of Crowdfunding Concerns in the Internet Age and the JOBS Act's Safeguards. Administrative Law Review, 2 (64): 474-505.

Word Spy (2008) Crowdfunding. Available at: http://wordspy.com/index.php?word=crowdfunding (accessed: 24.03.2017). 